\title{
O olhar local sobre o turismo na Rota Ecológica (AL)
}

\section{Local perception on tourism in the Rota Ecológica (AL, Brazil)}

\author{
Ana Rísia Soares Camêlo, Lindemberg Medeiros de Araujo
}

RESUMO: Com este trabalho, tem-se por objetivo analisar como os moradores das comunidades localizadas na área litorânea dos municípios de Passo de Camaragibe, São Miguel dos Milagres e Porto de Pedras, percebem a turistificação do seu lugar. Nessa parte do litoral norte de Alagoas, com 23 $\mathrm{km}$ de extensão, denominado localmente de Rota Ecológica, existem 13 pousadas sofisticadas, com uma oferta que se enquadra no eixo do turismo alternativo. Com características de sofisticação e exclusividade, combinadas com preocupação ambiental e práticas que valorizam a cultura local, essas pousadas apresentam aspectos que as ligam à concepção de pousadas de charme, com uma delas - Pousada do Toque - sendo membro da Associação [Nacional] de Hotéis Roteiros de Charme. Portanto, enquanto no restante do litoral alagoano a atividade turística tem tido como base o turismo de massa, com resorts e outros grandes equipamentos hoteleiros, a oferta da Rota Ecológica tem como base uma modalidade de desenvolvimento turístico alternativo, com fortes traços de sustentabilidade. A metodologia adotou uma abordagem qualitativa, com 0 uso de entrevistas abertas e entrevistas semiestruturadas junto a moradores antigos da área de estudo e observação direta. O estudo constatou que os entrevistados percebem mudanças na rotina da vida das comunidades relacionadas à chegada das pousadas. $\mathrm{Na}$ condição de antigos moradores do lugar, os olhares e sentimentos dos entrevistados indicam contradições, quando eles percebem ao mesmo tempo aspectos positivos, mas também problemas decorrentes da chegada da atividade turística em seu lugar. Neste trabalho são identificadas questões que oferecem novas oportunidades de pesquisa sobre o turismo desta parte do território alagoano.

PALAVRAS-CHAVE: Rota Ecológica; Turistificação; Percepção; Lugar. 


\section{ABSTRACT}

The objective of this work is to analyse how residents of communities of the coastal area of the municipalities of Passo de Camaragibe, São Miguel dos Milagres, and Porto de Pedras perceive the touristification of their place. In this part of the Alagoas' littoral, with an extension of $23 \mathrm{~km}$, which is locally called Rota Ecológica, there are 13 sophisticated small-scale luxury hotels with an alternative tourism offer. These hotels combine sophistication, exclusiveness, environmental concern, and practices that value the local culture in a way that link them up to the concept of charm. One of them, the Pousada do Toque, is a member of the national-scale Associação de Hotéis Roteiros de Charme. So, while the touristification of the rest of the Alagoas' state is based on mass tourism, with resorts and other large-scale tourism equipments, the offerings of the Rota Ecológica are based on alternative tourism, embedding strong sustainability elements. The study adopted a qualitative approach, with open interviews and semi-structured interviews which were run with residents that have lived in the region since before the arrival of the above-mentioned luxury hotels in the region and direct field observation. Results show that the interviewees perceive changes to the daily routines of their communities that in their views are a consequence of the tourism of these hotels. In the condition of long-standing residents of the region, the perceptions and feelings of the interviewees reveal contradictions in that they perceive both positive and negative aspects which result from the touristification of their place. In this work questions are identified that show new research opportunities regarding the touristification of this part of the territory of Alagoas state.

KEYWORDS: Ecological Route; Touristification; Perception; Place.

\section{Introdução}

O mundo vem passando por transformações econômicas e sociais profundas associadas ao processo de globalização, interferindo na forma como se dá a produção, consumo e sua relação com o espaço habitado. Parte da transformação tem ocorrido sob a influência do turismo, importante atividade contemporânea. As mudanças atuais podem ser o indício de uma transição entre o período moderno da História para uma nova ordem social. Alguns autores caracterizam esta fase como o início de um período pósmoderno, enquanto para outros trata-se ainda de um desdobramento do período moderno (GIDDENS, 1991; HARVEY, 2012). Essas alterações significativas vêm ocorrendo nas diversas sociedades ao redor do mundo. Independentemente de qual nomenclatura se dê ao fenômeno, pós-moderno ou desdobramento do moderno, o fato é que esses autores questionam o modelo moderno clássico.

O surgimento do turismo contemporâneo está normalmente associado ao período moderno (BARRETTO, 1995), sobretudo o turismo de massa. Um dos problemas grandes na disseminação desse tipo de turismo seria a sua saturação com o passar dos anos. Na maior parte dos destinos de sol e mar que são caracterizados pelo turismo de massa, as suas singularidades 
perdem força com o passar do tempo. Nesses lugares são instaladas ofertas padronizadas, diretamente concebidas com a finalidade de viabilizar os serviços de turismo nas destinações de forma excessivamente comercial, relegando-se a segundo plano aspectos importantes para a experiência do turista. A longo prazo, essa modalidade de turismo pode comprometer as margens de lucro esperadas.

Como consequência das transformações e impactos enormes (econômicos, sociais, culturais, políticos e ambientais) causados pelo turismo de massa nas últimas décadas, surgiram novas orientações de desenvolvimento com base no turismo. Trata-se de modelos ou formas alternativas da atividade turística não mais baseados nos clássicos modelos do turismo moderno, normalmente caracterizado por equipamentos hoteleiros de grande porte e por grandes fluxos de turistas, mas sim com base em modelos de escala menor, apresentando características mais brandas e alinhadas ao conceito do que se tem chamado de turismo responsável.

Esta orientação alternativa de turismo tem, de modo geral, valorizado a cultura dos lugares turísticos e a troca de experiências, estabelecendo e/ou fortalecendo os laços entre visitantes e visitados, e adequando-se às peculiaridades das localidades. Além disso, o turismo alternativo dinamiza as formas de apropriação do espaço habitado em uma escala menor, não consistindo exatamente de um segmento do turismo em si, mas sim de uma forma diferente do modo moderno de se fazer turismo, independente de segmentação, com formas que se encaixam a cada lugar e seu jeito de ser único ou singular. Nesse paradigma emergente, como posto por Cruz (2006) e por Costa (2001), as intervenções negativas relacionadas ao meio ambiente, cultura e cotidiano das comunidades receptoras são minimizadas.

Essa possibilidade emergente de se fazer turismo vem sendo disseminada e implantada em incontáveis lugares ao redor do mundo, tanto em países desenvolvidos, quanto nos países subdesenvolvidos. Na Jamaica, por exemplo, mais especificamente na praia de Treasure Beach (CONWAY; TIMMS, 2012) encontra-se um caso de turistificação de um lugar com praias paradisíacas, pouco frequentadas e com a instalação de meios de hospedagem de pequeno porte que ofertam serviços exclusivos de alta qualidade aos seus hóspedes.

Neste estudo tem-se como objetivo entender as percepções dos residentes das comunidades que formam a Rota Ecológica, litoral norte do estado de Alagoas, sobre a relação entre o turismo desenvolvido por 13 pousadas (Figura 1) que formam uma oferta alternativa ao turismo de massa no litoral de Alagoas e o cotidiano das pessoas do lugar. Busca-se entender quais são seus olhares e sentimentos em relação à dinâmica que esta nova atividade econômica tem provocado em seus lugares e comunidades. 


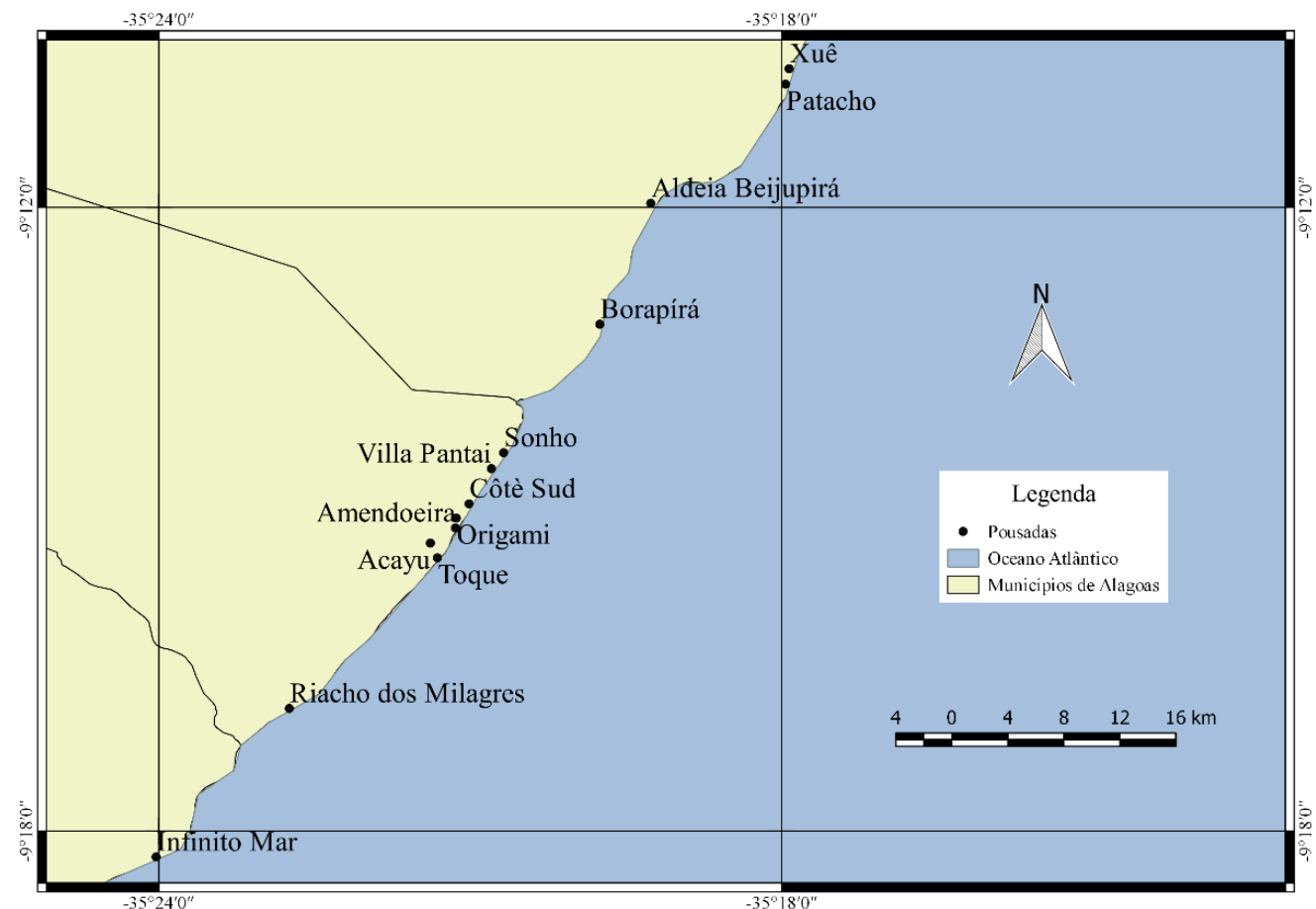

Figura 1: Localização e marcação das pousadas da Rota Ecológica. Fonte: LTTD/UFAL 2015 Figure 1: Location and marking of the hotels of the Ecological Route. Source: LTTD / UFAL 2015

O recorte espacial alvo deste estudo - a Rota Ecológica - é conhecido pela existência de pousadas singulares, de alguma forma associadas à noção de roteiros charme. Essa área é formada por um trecho de aproximadamente $23 \mathrm{~km}$ do litoral norte de Alagoas, com inúmeros lugares que apresentam características naturais, sociais, econômicas e culturais parecidas ou comuns entre si. Três municípios (Passo de Camaragibe, São Miguel dos Milagres e Porto de Pedras) formam esta rota que possui pequenos povoados, a maior parte dos quais localizada ao longo da rodovia AL-101 Norte, um lugar afastado da via principal que liga Barra de Santo Antônio a Maragogi (AL 105 e AL 465).

Neste trecho do litoral alagoano essa orientação ao turismo alternativo é até reconhecido pelas instâncias públicas locais e estaduais (ALAGOAS, 2011), porém já é possível ser observada também a chegada de grandes empreendimentos no modelo massivo a esta área. Como ao longo do tempo esse direcionamento vai se comportar dependerá de ações dos atores públicos e privados que atuam na região.

\section{Limitações do turismo de massa e possibilidades do turismo alternativo Diferentes possibilidades de desenvolvimento turístico}

A atividade turística de acordo com Archer e Cooper (1998) pode ser mais eficiente que outros tipos de atividades econômicas para gerar desenvolvimento em determinados lugares, especialmente por envolver mais a comunidade local, e assim promover um maior acréscimo na renda das famílias envolvidas. Ainda conforme os mesmos autores, se comparado a atividades econômicas como agricultura e indústria, o turismo, com as 
devidas precauções e planejamento, pode apresentar mais aspectos positivos do que negativos, mostrando-se, assim, promotor de uma maior equidade na distribuição dos benefícios gerados.

Desta forma, o turismo tem se apresentado como uma atividade econômica que pode contribuir para diminuir as desigualdades sociais como também pode valorizar as culturas locais nos lugares em que se estabelece (MENDONÇA, 2003), contribuindo para maximizar seus efeitos positivos e diminuir negativos (OLIVEIRA, 2008).

A atividade turística está presente em milhares de lugares ao redor do mundo, dos mais urbanizados aos mais rurais e exóticos (XAVIER, 2007). Por estar presente em diversos lugares do mundo que apresentam as mais diversas características, o turismo tem modificado os espaços de diversas formas, das mais massivas e clássicas, às formas alternativas e inovadoras. Quando o turismo apropria-se de um lugar, o processo de turistificação estará presente independentemente da orientação do turismo adotado pelo lugar ser de caráter alternativo ou de massa (RAMOS, 2010), ou seja, o lugar mudará inexoravelmente.

Esta transformação dos lugares através da atividade turística envolve três tipos de agentes e se dá da seguinte forma: a) turistas ${ }^{1}$, os quais são fundamentais na criação de lugares turísticos, apesar de serem relativamente esquecidos em benefício dos outros dois aspectos; b) mercado ${ }^{2}$, que é a fonte mais significativa de turistificação do espaço, sendo um dos agentes mais problemáticos, pois normalmente ignoram as comunidades e os interesses das destinações afetadas, com um foco exacerbado no lucro; c) planejadores e promotores 'territoriais's, que são uma das fontes mais influentes no desencadeamento de mudanças territoriais pelo turismo (KNAFOU, 1996, p.70), os quais envolvem também o próprio governo.

Seja qual for a composição dos agentes do turismo de um lugar, a área afetada passará por transformações, dentre as quais se espera que o turismo contribua para o desenvolvimento local e regional. Obviamente, as atividades turísticas não são a única saída para resolver os problemas sociais, mas podem contribuir significativamente para o alívio da pobreza dos lugares envolvidos, orientação que permeia grande parte da política oficial de turismo no Brasil nos últimos anos (BRASIL, 2005), principalmente se forem desenvolvidas de forma coletiva e se atendo às necessidades locais. É nesse sentido que Cruz, (2006, p. 342) argumenta que "O desenvolvimento do turismo deve ser um projeto construído coletivamente e não resposta a interesses particulares, de grupos sociais específicos".

Paradoxalmente, o turismo também pode gerar pobreza, dependendo de sua forma de apropriação dos lugares (CRUZ, 2006; EVANS, 2011), especialmente em modelos massivos de turismo como é caso dos resorts. Caso a atividade turística seja desenvolvida buscando-se o benefício para as comunidades envolvidas, poderá em teoria haver uma maior contribuição do turismo para a redução das desigualdades nos lugares em que se instala. Nos termos de Coriolano (2009), é o caso do turismo comunitário, em que a população é detentora do poder de decisão em seus lugares, mantendo o 
controle sobre o desenvolvimento da atividade, sobre os lucros e sobre a sua distribuição no âmbito da comunidade.

\section{O Turismo de Massa}

O turismo de massa surge principalmente como consequência do aumento da produção e consumo de massa de outros setores econômicos, como, por exemplo, o da indústria. As férias remuneradas e a organização do trabalho e do lazer, conquistas dos trabalhadores pós-revolução industrial, também contribuíram para impulsionar o desenvolvimento da atividade turística em grande escala. Contudo, foi necessário um tempo de adaptação e mudanças para que esses fatores contribuíssem para a atividade turística no mundo, já que neste período o turismo era reservado às elites. Segundo Boyer (2003, p. 31), "o turismo contemporâneo é o herdeiro das formas elitistas. Passou-se de um pequeno número às massas sem revolucionar 0 conteúdo". Um importante impulsionador do turismo foi o surgimento do carro popular, que com a sua difusão e posteriormente facilidades no sistema de crédito com o parcelamento do pagamento, tornou mais fácil os deslocamentos individuais, fazendo assim com que cada vez mais pessoas pudessem praticar turismo e não só mais as elites.

O modelo massivo de turismo "[...] se refere à produção de turismo organizado industrialmente, que apoia o movimento de grandes números de pessoas [...]" (COOPER; HALL; TRIGO, 2011, p. 39), ou, em outras palavras, se refere à produção em larga escala. Porém vale lembrar o argumento de Cruz (2003, p.6) de que mesmo sendo considerada uma produção em massa, está longe de esse número corresponder à população mundial, pois as massas populacionais excluídas de condições socioeconômicas mínimas de subsistência, não possuem condições financeiras de praticar turismo.

Além disso, com a internacionalização da atividade turística teve início uma busca por lugares exóticos e preservados, como o litoral de países em desenvolvimento. A partir de então, o capital internacional passou a procurar as regiões detentoras de natureza e cultura singulares para investimentos com base no turismo. Os grandes grupos econômicos buscam nesses lugares um investimento lucrativo para o seu capital, já que nos países desenvolvidos tais espaços são escassos, como também vão em busca de uma flexibilidade das leis para sua instalação.

As regiões intertropicais, detentoras de grandes estoques de natureza preservada, passaram a ser um dos principais alvos da demanda turística internacional, com a mobilização de grandes volumes de capitais para investimento, através de financiamentos obtidos de agências transnacionais, sob a retórica, assumida pelos governos locais e obviamente pela iniciativa privada [...] da necessidade de se "desenvolver" essas áreas (ARAUJO; MOURA, 2007, p.96). 
Assim esses grandes empreendimentos de turismo, com base especialmente em resorts, copiam o modelo empregado pelas multinacionais de atividades econômicas que dominam o mercado de lazer e se instalam preferencialmente em lugares periféricos em que a mão de obra utilizada é mais barata e os lucros auferidos, normalmente altos, são transferidos ao país de origem dos investimentos (CORDEIRO; BENTO; BRITTO, 2011).

Esta forma de turismo oferece principalmente hospedagens que prezam pelo conforto e facilidades na hospedagem, oferecendo todos os produtos e serviços que os hóspedes precisam sem ser necessário que eles procurem serviços fora do hotel ou resort, mantendo-se desta forma alheio ao entorno e comunidades locais (MARSON, 2011). O modelo dos enclaves de resorts são os mais emblemáticos exemplos da massificação da atividade turística, apoiado em um paradigma que governou o progresso técnico e a expansão econômica no mundo nos dois últimos séculos. É um exemplo representativo do período Moderno, como pode ser observado através do conceito de turismo de massa por Urry (1990, p.23):

Isolado de um ambiente acolhedor e das pessoas locais, o turismo de massa promove viagens em grupos guiados e seus participantes encontram prazer em atrações inventadas com pouca autenticidade, gozam com credulidade de 'pseudo-acontecimentos' e não levam em consideração o mundo 'real' em torno deles.

No Nordeste, o incentivo ao turismo de massa, à criação e ampliação de infraestrutura, e à implantação de empreendimentos privados, se acentuou principalmente após a criação do Programa para o Desenvolvimento do Turismo no Nordeste (PRODETUR-NE). Outros programas federais - como a Política de Megaempreendimentos, também chamada de Megaprojetos Hoteleiros (DUDA, 2013) - também contribuíram para o desenvolvimento do turismo no Nordeste, tendo gerado significativo crescimento econômico.

Entretanto, o turismo de massa, objeto das mencionadas políticas, é considerado como um dos modelos de turismo mais opressores e excludentes, tanto para os turistas quanto para as comunidades locais (RODRIGUES, 2006). Devido principalmente à sua negligência com as características econômicas, sociais e culturais dos lugares explorados, 0 turismo de massa tende a prejudicar mais do que proporcionar benefícios para as comunidades em que se insere. Os residentes acabam tendo que arcar economicamente com as mudanças feitas em seu lugar em prol do turismo (PANOSSO NETTO, 2010). Entretanto, seu poder aquisitivo é pequeno para que possam arcar com custos adicionais no orçamento da família. Muitas vezes, os equipamentos que passam a existir nesses lugares turísticos não são de necessidade das comunidades, mas sim dos turistas.

Ainda em relação à presença do modelo massivo de turismo em muitos destinos estudados ao redor do mundo, várias pesquisas têm identificado alterações negativas causadas por esse modelo. É, por exemplo, o que vem acontecendo em diversos destinos turísticos como em Porto de Galinhas 
(PE), Praia do Forte (BA) e Pipa (RN) (BRANDÃO, 2013) e o estudo de Bihu, Min e Xiaoli (2012) sobre o impacto no patrimônio mundial da Unesco na cidade antiga de Ping Yao, na China.

Apesar de todos os aspectos negativos já relacionados ao turismo de massa, no Brasil esse modelo se encontra em pleno desenvolvimento (CORDEIRO; BENTO; BRITTO, 2011). De acordo com a OMT (2006), na realidade, o turismo de massa ainda está em sua "fase de infância", afirmando a existência de milhares de lugares ao redor do planeta a serem apropriados e utilizados por essa orientação turística. O turismo de massa é um modelo que além do maior exemplo de enclave como os resorts, também se dá de maneira excludente como em cidades inteiras, especialmente em destinos de sol e mar com outros tipos de hospedagens, em hotéis e pousadas menores.

O paradigma moderno, conhecido por suas formas rígidas, vem passando por transformações, e um novo olhar e maneira de ver e viver no mundo está em desenvolvimento. Nessa direção e de acordo com Marson (2011), o modelo dos resorts vem se adaptando a esta nova fase do turismo, buscando inserir o conceito de sustentabilidade em seus estabelecimentos, principalmente após os anos 1990. Por fim, chega-se à conclusão de que ou este modelo se adapta, ou provavelmente poderá ficar fora do mercado emergente na sociedade atual em longo prazo.

\section{Turismo Alternativo}

O turismo como atividade econômica surgiu e tem evoluído nos moldes modernos de sociedade, tendo seu funcionamento e razão de ser intrinsecamente ligado ao desenvolvimento do capitalismo. Na sociedade atual, surgiram modos mais flexíveis de acumulação do capital. "Vemos, há vinte anos, o aumento do turismo verde, do qual as zonas de Natureza, o Campo tiraram grande proveito" (BOYER, 2003, p.164). O turismo alternativo possui características que se vinculam ao momento pós-moderno da sociedade, com uma proposta de lazer centrada na alteridade, no singular, ou em outras palavras, numa experiência que parece buscar a negação da pressa, da rotina, de um ethos que foi criado com a emergência do período moderno. Contudo, para alguns autores, a exemplo de Harvey (2012), esse novo tipo de comportamento por parte de determinados setores sociais ainda não é o surgimento de uma nova sociedade e sim apenas o ápice do momento moderno da sociedade.

Apesar da complexidade e discordância de autores sobre este tema, o fato é que mudanças significativas vêm ocorrendo nas sociedades e questionam o conceito de modernidade clássico, independente de qual nome se dê ao fenômeno,

Mudanças sociais e culturais sem precedentes estão acontecendo; se 'pós-modernidade' é ou não o melhor termo para consubstanciar essas mudanças é uma questão controversa [...] Pós-modernidade é um termo que, para o momento, cumpre bem sua finalidade (LYON, 2005, p.128). 
Os modelos alternativos de turismo surgem de forma mais clara a partir da década de 1980, década em que os debates e a evolução dos conceitos relacionados ao turismo sustentável e ecoturismo começaram a ter relevância no cenário mundial (COOPER; HALL; TRIGO, 2011). Esse novo direcionamento de turismo vem sendo difundido ao redor do mundo nas últimas décadas e ganhou força nos últimos anos com a proliferação de um maior número de lugares que aderiram a este perfil, tanto em países desenvolvidos quanto em desenvolvimento, como, por exemplo, no mencionado caso da Jamaica, na praia de Treasure Beach, (CONWAY; TIMMS, 2012), e também vem ocorrendo em lugares consagrados de ecoturismo, a exemplo no Brasil, os destinos de Bonito no Mato Grosso do Sul e da Chapada Diamantina, na Bahia.

Lugares que se alinham a formas alternativas de turismo, com características rústicas e peculiares, têm sido um dos novos alvos do mercado turístico. São localidades que propiciam ao visitante o contato com uma dinâmica diferente do seu cotidiano, apresentando as danças e folclore locais, valorizando o modo de ser local e os elementos dos lugares visitados. Nessas experiências turísticas, "São as danças, as festas, os ritmos, os artesanatos e até a maneira de ser de algumas populações os elementos valorizados como atraentes" (MENDONÇA, 2003, p.47). Trata-se de um fenômeno sociocultural novo ligado ao turismo, pois:

\begin{abstract}
Agora não se trata mais de regiões subdesenvolvidas, ou da periferia do capitalismo, mas de regiões com peculiaridades locais que the conferem um desenvolvimento específico, diferenciado, especial (RAMOS, 2010, p.28).
\end{abstract}

Na visão de Krippendorf, "mais ou menos no longo prazo, os novos conceitos do turismo vão se impor de maneira geral' (2009, p.107). Ou seja, aos poucos, esses novos conceitos e desdobramentos da atividade turística vão se adequando às localidades, aproveitando as suas peculiaridades, amenidades e singularidades. Estas formas da prática turística se adequam aos lugares, fazendo com que as intervenções feitas no meio ambiente, cultura e cotidiano locais por causa do turismo sejam minimizadas.

Deste modo, percebe-se que há uma tendência a uma reorientação parcial da atividade turística para atender às mudanças de paradigmas sociais e culturais que estão ocorrendo no mundo, mas nem por isso são formas que se opõem totalmente à lógica do modo capitalista de produção. Trata-se sim de uma nova abordagem de desenvolvimento turístico, na busca de inovação da sua capacidade de administrar a própria dinâmica de mercado, oferecendo novos produtos para o sistema continuar fluindo, a despeito de suas contradições.

Um dos problemas da atividade turística contemporânea é que "a oferta turística se encontra na incapacidade de manter seu ritmo normal e se vê, assim, na obrigação de inovar para atender às novas necessidades" (ZAOUAL, 2008, p.3), e assim é que os modelos alternativos de turismo 
ganham espaço para desenvolverem-se. Os lugares turísticos que estão caminhando para vertentes da segmentação do turismo alternativo, vêm apresentando mais pontos positivos em relação aos impactos da atividade do que negativos nos destinos turísticos, como exemplificado nos estudos de Coriolano (2009) na Prainha do Canto Verde, Ceará, através do turismo comunitário.

Nos lugares turísticos que vem aderindo aos modelos alternativos de turismo, em que o contexto socioeconômico e cultural se encontra de alguma forma preservado, também vem se apresentando mais possibilidades de incremento econômico através do artesanato, da pesca, da agricultura familiar, e de outras atividades tradicionais locais. São atividades que apresentam aspectos agregados à oferta turística local, beneficiando assim as comunidades que aderem à atividade turística. Na prática, as atividades econômicas locais pré-existentes complementam o produto turístico local, já que estes aspectos são valorizados e apreciados pela orientação de turismo alternativo.

Ao que parece, esta é a forma de se fazer turismo que mais tem se importado com os residentes e os problemas advindos da atividade turística. Como diz Nicoletti (2003), na realidade parece haver dois movimentos contraditórios em curso na sociedade: o primeiro padronizador, comandado pelo mercado de massa; o segundo diferenciador, valorizando a identidade do indivíduo, suas singularidades, marcado pelos grupos sociais de representatividade local. E no mesmo tipo de raciocínio Boyer (2003, p.164) complementa:

\begin{abstract}
Ao mesmo tempo em que mudam os gostos, em que nascem as modas e enfraquecem-se os entusiasmos das estrelas, modifica-se a parcela respectiva das categorias de população, algumas muito sensíveis aos novos patterns (os jovens, por exemplo), outras em fase de recuperação das privações passadas (terceira idade).
\end{abstract}

Com isso os modelos vinculados às formas alternativas de turismo são os que mais se encaixam no perfil dos moldes de turismo implementados na Rota Ecológica através das pousadas do estilo charme. Essa forma do turismo se fixar nos lugares ocorre na área da Rota Ecológica, apesar de nos últimos anos projetos de modelos referentes ao modo massivo do turismo, especialmente resorts, já se apresentarem também como uma possibilidade nesta mesma localidade, em pelo menos duas praias da região (Praia de Morros - Barra de Camaragibe e Praia do Patacho - Porto de Pedras), como também já está em execução a construção de loteamentos e condomínios fechados (Figura 2). 


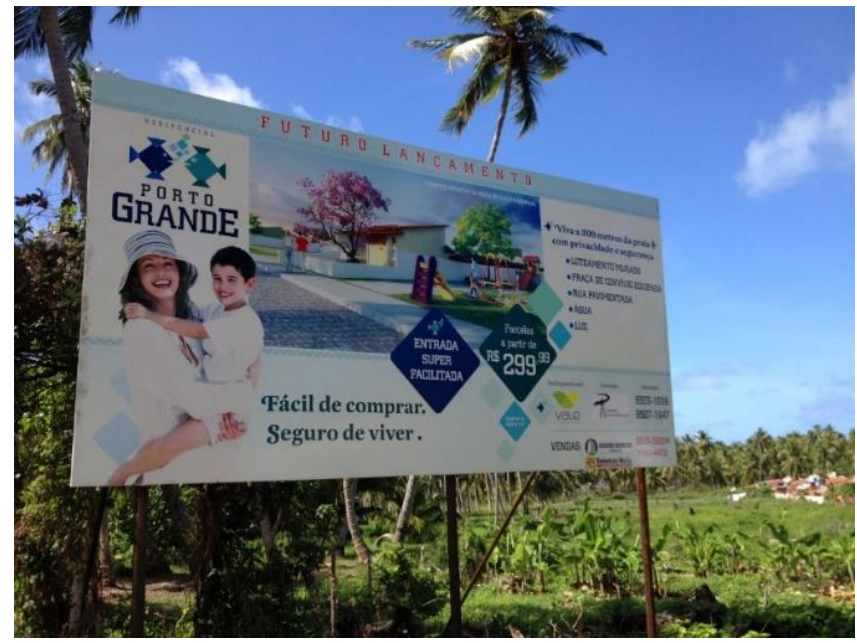

Figura 2: Placa de vendas de loteamentos e condomínios fechados na área da Rota Ecológica - Município de Porto de Pedras. Fonte: LTTD/UFAL 2015.

Figure 2: Sales plaque of subdivisions and condominiums closed in the area of the Ecological Route - Municipality of Porto de Pedras. Source: LTTD / UFAL 2015

Assim, formas contraditórias de inserção do turismo têm se apresentado nessa área do litoral alagoano. Por um lado, constatam-se formas alternativas (pousadas), e, por outro lado, verifica-se a emergência de consumo turístico do espaço associado ao eixo massivo (resorts, segunda residência, etc.), com maior potencial de transformar o cotidiano das comunidades locais ao longo do tempo. O modelo alternativo local, apesar de algumas críticas recebidas, ainda é o que apresenta menores efeitos negativos sobre os lugares e populações estudados neste trabalho.

\section{Metodologia}

Nesse estudo foi estudada a percepção da população autóctone das comunidades litorâneas localizadas ao longo do trecho do litoral alagoano pertencente aos municípios de Passo de Camaragibe, São Miguel dos Milagres e Porto de Pedras, entre a foz do rio Camaragibe e a foz do rio Manguaba, sobre a inserção de 13 pousadas nos lugares que eles habitam, especificamente na área conhecida localmente como Rota Ecológica. A metodologia adotou uma abordagem qualitativa, com o uso de entrevistas abertas e entrevistas semiestruturadas junto a moradores antigos da área de estudo, e observação direta.

O estudo se apoiou na concepção geográfica da percepção, ligada à Geografia Humanística e em concepções filosóficas da fenomenologia e existencialismo. A percepção é entendida por Merleau-Ponty (1999) como um evento que vai além das impressões que o ser humano possui sobre sua realidade. Já a fenomenologia é uma das correntes filosóficas que explica a relação dos homens com os outros no mundo. Também é utilizada em larga escala pelos estudos da psicologia. Criada pelo filósofo Edmund Husserl, a fenomenologia desvenda os fenômenos implícitos nas relações humanas, suas intencionalidades na relação com o outro, além de compreender os fenômenos tais como eles parecem ser (EWALD, 2008). Na mesma linha de raciocínio, o Existencialismo também contribui para a formação do 
pensamento Fenomenológico. Essa concepção filosófica chegou ao seu apogeu na década de 1950, no período pós-guerra, disseminado principalmente pelo filósofo dinarmaquês Søren Kierkegaard e Jean Paul Sartre. Essa linha filosófica responsabiliza o homem sobre o seu destino e defende o livre arbítrio dos seres humanos. Há assim de certo modo neste pensamento um privilégio da vivência subjetiva em detrimento da realidade objetiva.

Ao total, foram entrevistadas 12 pessoas, selecionadas a partir da reunião de características importantes para este estudo. Os entrevistados moravam há mais de vinte anos e/ou nasceram no lugar e viviam nele no momento da entrevista. Foram incluídos nas entrevistas membros das colônias de pescadores locais, representantes de associações ligadas ao turismo local, comerciantes ligados ao turismo e pessoas dos lugares estudados que, segundo levantamentos exploratórios junto a diversos indivíduos, moram há bastante tempo nesses lugares e possuem conhecimento e vínculos profundos com eles. Destes, três entrevistados foram do povoado de Barra de Camaragibe, pertencente ao município de Passo de Camaragibe; seis de São Miguel dos Milagres; e três do município de Porto de Pedras. O município de São Miguel dos Milagres teve a maior quantidade de entrevistados já que também possui a maior quantidade de pousadas pertencentes à Rota Ecológica.

A percepção geográfica do turismo pelos residentes é uma importante maneira de estudar os destinos turísticos, pois através dos autóctones se pode ter uma visão abrangente dos aspectos modificadores dos lugares. Segundo Xavier (2007), depois de uma convivência com as atividades turísticas no seu lugar por um período relativamente longo de tempo, as populações envolvidas desenvolvem uma percepção sobre as mudanças trazidas pelo turismo para o seu lugar, daí a relevância de ouvir essas vozes locais.

Esta percepção tem em sua base a geografia humanística e "[...] encontra seus fundamentos na fenomenologia e no existencialismo, e valoriza as experiências do homem em seu meio" (XAVIER, 2007, p.27). Essa concepção de percepção nada mais é do que a percepção que os homens têm do meio em que vivem, suas relações com as atividades existentes no seu lugar, sejam essas atividades ligadas aos setores econômicos sociais, culturais ou ambientais, ou seja, em outras palavras, é a percepção de indivíduos das comunidades receptoras, a partir da valorização dos recursos dos seus lugares pelo turismo.

Não levar em consideração o que a população residente sente com a instalação do turismo em seu lugar, é um dos erros mais recorrentes nas destinações turísticas do Brasil. Através da percepção geográfica do turismo, pode-se conhecer a relação entre as pessoas e o espaço construído pelo turismo, seja ele de massa ou de base local. Nessa perspectiva, para Xavier (2007, p.62), "[...] torna-se necessário considerar os sentimentos das pessoas, seus laços afetivos com o meio ambiente e suas atitudes em relação ao lugar". Logicamente, cada grupo com sua visão de mundo particular irá ter 
uma percepção sobre o turismo de maneira diferente. Por isso a importância de se ouvir os atores envolvidos na atividade.

A elaboração do roteiro de entrevistas foi feita com base em aspectos econômicos, sociais, culturais e ambientais do lugar, inspirados nos tipos de mudanças que a atividade turística pode desencadear nos lugares nos quais se insere, usando como referência Panosso Netto (2010). Nesse sentido, o entendimento para este trabalho é que os mencionados aspectos são algumas das características mais relevantes dos lugares; com base neles os residentes desenvolvem uma percepção geográfica (XAVIER, 2007) do seu lugar. Para Baker e Saren (2010), a percepção é um processo cognitivo de cunho psicológico pelo qual a pessoa vivencia e atribui sentido a tudo que está ao seu redor, selecionando, organizando e interpretando os fenômenos percebidos. Sendo assim, ao interrogar o indivíduo que vivencia o fenômeno que quer entender, o pesquisador tem acesso a material que permite a ele examinar a questão ou questões que fazem parte da pesquisa que ele está conduzindo; foi dessa forma que se procedeu metodologicamente neste trabalho.

\section{Rota Ecológica: Litoral Norte de Alagoas}

A área onde se localizam as pousadas da Rota Ecológica é formada por três municípios do litoral norte do estado de Alagoas, a saber: Passo de Camaragibe, São Miguel dos Milagres e Porto de Pedras. Essa área se encontra entre a foz dos rios Camaragibe e Manguaba. São lugares afastados da rodovia que conecta a cidade de Barra de Santo Antônio a Maragogi e tal isolamento fez com que esses lugares não contem ainda com grandes fluxos turísticos, como observados no restante do litoral norte alagoano, os quais se concentram no trecho entre Maceió e Barra de Santo Antônio e no trecho entre Japaratinga e Maragogi (CAMÊLO, 2013).

A Rota Ecológica posiciona-se entre os dois trechos mais movimentados do litoral norte alagoano, em municípios pequenos e que ainda preservam boa parte de suas características culturais tradicionais e naturais. A primeira pousada foi instalada na região em 1999 - Pousada Côté Sud (CARVALHO, 2014) e desde então o aumento delas vem se dando a cada ano, não só com pousadas deste estilo, mas também com outros equipamentos turísticos da região, como restaurantes gourmet, bares e espaços para day use, além da oferta de outros serviços no mesmo padrão de conforto e alta gastronomia. Além disso, estes lugares apresentam características naturais, sociais, econômicas e culturais parecidas, compostas por pequenos povoados de raízes históricas parecidas.

Em uma perspectiva socioeconômica, a Rota Ecológica é marcada historicamente por problemas associados à pobreza, afetando a maior parte de sua população. De acordo com o estudo do Master Ecopolis (2010) destaca-se entre as principais atividades econômicas desta área o cultivo intensivo de cana-de-açúcar, localizado nas terras mais afastadas do mar, no interior desses municípios. Ainda de acordo com esse estudo, outras atividades tradicionais locais também são identificadas como a pesca, a 
produção de coco e a agricultura familiar de subsistência com base na produção de produtos tais como mandioca, banana, feijão e milho. A pesca nesta área é uma das atividades mais antigas, e apresenta duas formas: a artesanal, com maior predominância; e a industrial em menor escala.

A atividade turística vem se desenvolvendo nos últimos anos nessa região e está concentrada nas áreas próximas à orla marítima. Nesta área, o ICMBIO (Instituto Chico Mendes de Conservação da Biodiversidade), juntamente com a comunidade promoveu a criação da Associação de Condutores do Passeio de Turismo de Observação do Peixe-boi em Tatuamunha, povoado de Porto de Pedras, pertencente à Rota Ecológica. Tal projeto vem ganhando visibilidade nacional nos últimos anos e promovendo além da preservação da espécie, a geração de renda para a comunidade local. Como também esta mesma instituição e seus projetos vêm fortalecendo de alguma forma o senso de cooperativismo entre os residentes, tanto para promover o turismo como para garantir seus direitos sobre o lugar. Assim, o turismo, junto com as demais atividades econômicas tradicionais, é um ponto forte da sociedade local, fortalecendo o sentimento de pertencimento ao lugar por parte das comunidades locais. Essas atividades representam mais um elemento na formação do produto turístico da Rota Ecológica, inovando e diversificando a economia, como parte das cadeias produtivas locais.

A área que forma a Rota Ecológica apresenta uma rica pluralidade em recursos ambientais, culturais e sociais. São valores e saberes que estão presentes sutilmente no cotidiano das comunidades locais e que para as formas de turismo alinhado às ofertas alternativas são elementos fundamentais. Essa orientação de turismo da Rota Ecológica se apresenta de forma diferente do que vem ocorrendo no restante do litoral norte de Alagoas, onde há o predomínio do turismo de massa, fortalecido principalmente pelo programa de turismo Costa dos Corais através do Prodetur/NE (BANCO DO NORDESTE, 2011).

A orientação turística praticada pelas pousadas da Rota Ecológica recebe influência de alguma forma do chamado "turismo de charme", em que os Roteiros de Charme apresentam em seus meios de hospedagem no Brasil as seguintes características principais: poucos apartamentos, bangalôs ou chalés; decoração dos ambientes baseada no charme; exclusividade e atendimento personalizado dado aos clientes; preocupação com aspectos ambientais ligados à gestão ambiental, como reciclagem do lixo, uso de fontes alternativas de energia, uso de produtos orgânicos, plantação de hortas, além da participação dos estabelecimentos em projetos ambientais e sociais nos lugares que se instalam (ROTEIROS DE CHARME, 2012). Especificamente na Rota Ecológica, a Pousada do Toque é a única que faz parte da Associação [Nacional] de Hotéis e Roteiros de Charme. Entretanto, mesmo não participando da Associação de Hotéis e Roteiros de Charme, as demais pousadas da Rota Ecológica possuem o mesmo estilo e filosofia acima citados. Quanto à origem dos proprietários dessas pousadas, a maioria é formada por estrangeiros e têm no seu quadro de funcionários principalmente pessoas das comunidades nas quais se localizam. 
A região da Rota Ecológica vem recebendo destaque nos últimos anos, não só pelos turistas, assim como também pelo poder público alagoano, que enxerga nessa região novas oportunidades de crescimento econômico e desenvolvimento para o estado. Tal fenômeno, talvez esteja ocorrendo pela procura de formas alternativas de turismo que procurem unir a contemplação da beleza cênica dos lugares a serviços de qualidade, relações e novos sentidos existenciais para viagens (ZAOUAL, 2008). Nessa região, a proposta inicialmente foi criada pelas pousadas da Rota Ecológica e depois desse primeiro interesse da iniciativa privada, as comunidades locais também começam a oferecer produtos e serviços turísticos, assim como o setor público também inicia ações de divulgação turística dessas localidades, sugerindo que a atividade turística será a melhor opção para o desenvolvimento local. No âmbito de políticas públicas e legislação direcionadas a essa localidade destaca-se a Lei № 7.231, de 7 de Janeiro de 2011 (ALAGOAS, 2011) que prevê prioridade para a instalação de pousadas com o mesmo estilo das existentes nesses lugares, e que se assemelham aos empreendimentos associados à filosofia dos roteiros de charme.

\title{
Percepções das comunidades locais sobre o turismo das pousadas da Rota Ecológica
}

Este estudo constatou que os entrevistados das comunidades locais estabelecidas na área da Rota Ecológica percebem mudanças significativas na rotina de vida local com a chegada das pousadas. Os olhares e sentimentos da população local indicam também contradições, pois ao mesmo tempo que os entrevistados observam aspectos positivos, também visualizam problemas acarretados pela chegada do turismo no seu lugar. Com base no índice de irritação proposto por Doxey (1975) - Irridex (Quadro 1) -, os indivíduos que já moravam nestes lugares antes do início da chegada das referidas pousadas parecem se situar na fase de apatia. Por exemplo, verificou-se que os entrevistados tendem a valorizar os visitantes. Em parte, porque dentre eles há artistas, desportistas famosos e outras celebridades, o que parece conferir certo grau de status a esses lugares, consequentemente com possíveis efeitos sobre a autoestima dos residentes antigos. Em parte também, porque as pousadas e os seus hóspedes geram emprego, ocupação e aumento da renda local, em lugares com poucas possibilidades de desenvolvimento econômico, como pode ser exemplificado na fala abaixo:

\begin{abstract}
"Eu mesmo, a minha opinião pessoal, eu me sinto muito bem, porque eu vejo que o município tá recebendo divisa, o bugueiro ganha se não tiver o agenciador, vai vender um refrigerante, o outro vai vender um almoço, um cara passa ali na esquina compra um artesanato, e assim sucessivamente, e as pessoas gostam, tem uma aceitação muito boa com os turistas" (E2).
\end{abstract}

Verifica-se, com base na percepção deste entrevistado sobre a chegada do turismo na Rota Ecológica, uma ênfase nos benefícios 
econômicos proporcionados pelo turismo das pousadas. Isso parece denotar a necessidade de investimentos no desenvolvimento local, uma vez que essa parte do Estado de Alagoas apresenta indicadores socioeconômicos baixos, principalmente por causa da crise do setor canavieiro, tradicionalmente 0 principal esteio da economia regional.

Quadro 1: Modelo Irridex de percepção do turismo pelos residentes de um destino turístico.

Table 1: Irridex model of tourism perception by the residents of a tourist destination.

\begin{tabular}{|c|c|}
\hline \multicolumn{2}{|c|}{ MODELO IRRIDEX DE DOXEY } \\
\hline Fase & Relações Sociais \\
\hline Euforia & $\begin{array}{l}\text { Fase inicial do desenvolvimento turístico, na qual } \\
\text { visitantes e investidores da atividade são bem } \\
\text { vindos. O turismo é visto como fonte de emprego } \\
\text { e renda pelos residentes }\end{array}$ \\
\hline Apatia & $\begin{array}{l}\text { Os visitantes são valorizados. O turismo é visto } \\
\text { como uma atividade de lucros. O contato entre } \\
\text { visitantes e visitados é mais formal. Existe o } \\
\text { predomínio de interesses comerciais no contato } \\
\text { com turistas por parte dos residentes }\end{array}$ \\
\hline Irritação & $\begin{array}{l}\text { Residentes tornam-se saturados com a chegada } \\
\text { de turistas e passam a desconfiar e duvidar dos } \\
\text { benefícios da indústria turística }\end{array}$ \\
\hline Antagonismo & $\begin{array}{l}\text { O nível de irritação dos residentes é } \\
\text { amplamente expresso. Os visitantes são } \\
\text { vistos como a causa de todos os problemas. }\end{array}$ \\
\hline
\end{tabular}

Fonte: Adaptado de (DOXEY apud PANOSSO NETTO, 2010).

Source: Adapted from (DOXEY apud PANOSSO NETTO, 2010).

Os entrevistados demonstraram certa preocupação com a expansão do turismo de massa no seu lugar, principalmente o modelo resorts, que, se materializado, poderá levar à emergência no futuro, de uma fase de irritação (DOXEY apud PANOSSO NETTO, 2010) frente à turistificação da Rota Ecológica sobre outra orientação mercadológica, seguramente de massa, como abordado por um morador a seguir:

[...] "mas tem uns que chega às vezes e diz: "ah eu não gostei daqui porque aqui não tem estrutura, porque aqui..." mas não vê que aqui é um lugar pequeno, tá começando agora. E se tivesse mais estrutura tenho certeza que não seria assim. Seria horrível, seria como uma cidade, muito poluída, e... não ia ter muito... ia ter mas iria tá [sic] lá embaixo, mas hoje Graças a Deus tá lá em cima" (E6).

A fala desse entrevistado não é comum ao se entrevistar pessoas de comunidades que se tornaram território do turismo no litoral alagoano. Frequentemente, acredita-se que o turismo de grande escala, com resorts e 
grandes hotéis, será a redenção econômica do lugar (VASCONCELOS, 2017). A preocupação desse entrevistado em relação aos impactos negativos que o turismo pode causar alinha-se de alguma forma às proposições do desenvolvimento sustentável.

A área da Rota Ecológica é constituída por povoados de porte pequeno, e que com a chegada da atividade turística, iniciada pela instalação das pousadas em questão, vem ganhando significativa visibilidade. Até então, estes lugares eram desconhecidos por pessoas de fora desses municípios e região, e atualmente recebem visitantes de várias partes do mundo. Após a chegada das pousadas da Rota Ecológica, muitos aspectos relacionados às dinâmicas do espaço local mudaram. Como nos diz Rodrigues (1999), o cotidiano de povoados desse tipo normalmente apresenta alterações causadas pelo turismo que de certo modo jamais podem ser revertidas, sejam aspectos culturais, ambientais, sociais ou econômicos.

Nos aspectos ambientais, este estudo verificou que as comunidades da Rota Ecológica, antes da chegada das pousadas, possuíam pouca ou quase nenhuma preocupação com as questões ambientais, como mencionado pelo entrevistado a seguir:

"E...isso em 2002 eu tava [sic] de frente a pousada do Toque, nuns [sic] curral [sic], tem vários currual [sic] lá de frente lá, e eu...eu joguei o plástico. Uma turista foi pegou o plástico, foi lá: "Bom dia" eles são sempre bem educado, bom dia [...] "quem é o responsável por aqui, você é o dono dali?" Não. "Mas quem é o responsável da obra?" Não, sou eu, pronto. "Olhe o senhor está errado, olhe aqui, esse saco aqui vai levar quinhentos anos pra acabar". Foi uma coisa que ela fez comigo e eu nunca esqueci. E agora veio a lembrança, quer dizer, reeduca" (E5).

Essa postura de um visitante da Rota Ecológica mostra como, apesar de o turismo ter o potencial de degradar ambientalmente os destinos, ele também pode contribuir para a criação de atitudes pró-sustentabilidade, 0 que, até certo ponto, depende do perfil da demanda turística de cada lugar visitado. O comportamento comunicado pelo entrevistado talvez resulte do fato da população local ter vivido durante muito tempo apenas com seus recursos naturais e de haver pouca interferência externa que pudesse causar danos ambientais significativos, e também pela pouca atuação dos órgãos de meio ambiente na região anteriormente.

Neste estudo, também ficou claro que o problema ambiental maior, na percepção dos moradores, não é causado pelas pousadas da Rota Ecológica e sim pelos próprios membros da comunidade, que ainda não possuem um direcionamento educacional para tratar de conservação e preservação ambiental, e também pela omissão do poder público local, que não tem cumprido com suas obrigações institucionais em relação às questões ambientais. Além disso, a presença das pousadas da Rota Ecológica, juntamente com as propostas do ICMBIO, faz com que as questões 
ambientais que afetam as comunidades locais sejam trabalhadas mais efetivamente, contribuindo com a conservação do meio ambiente.

Em relação aos aspectos culturais, alguns autores explicam que em muitos lugares ao redor do mundo o turismo pode ser o elemento que irá garantir a manutenção de certas tradições originais que atraem os turistas, obviamente se esta atividade for bem gerenciada e planejada (ARCHER; COOPER, 1998). Este estudo identificou que apesar das pousadas terem uma visão mercadológica, elas ajudam a fortalecer valores e o patrimônio cultural das comunidades, estimulando uma participação ativa da população na atividade turística local, mesmo que ainda em baixa escala e sem o apoio dos poderes públicos locais, como no exemplo da próxima fala:

\begin{abstract}
"Era que isso aí, seria até um incentivo. A pousada do Toque ainda tentou fazer isso várias vezes. Quando tinha o projeto, ela levava o...a quadrilha pra [sic] incentivar, queria criar quadrilha pra [sic] fazer isso. A única pousada que incentivou, foi a pousada do Toque" (E2).
\end{abstract}

Por estarem inseridas na orientação de turismo alternativo, com características similares, por exemplo, às ofertas do slow tourism (HEITMANN; POVEY; ROBINSON, 2011), as pousadas da Rota Ecológica têm contribuído para a manutenção da cultura local. Os aspectos culturais locais também são relativamente valorizados e incentivados por parte dos pousadeiros, que veem o patrimônio cultural local como um importante elemento dos atrativos disponíveis para seus hóspedes.

Quanto aos aspectos econômicos em geral, alguns autores observam que a renda das populações de destinos turísticos pode ser incrementada pela atividade turística. Por exemplo, segundo Archer e Cooper (1998), o turismo pode trazer significativos impactos econômicos para lugares periféricos e com pouco desenvolvimento. "Em tais lugares uma grande parte da população vive da agricultura de subsistência ou são pescadores, e quando se envolvem na indústria do turismo sua renda familiar sofre um acréscimo bastante grande em termos relativos" (p.88).

As pousadas da Rota Ecológica proporcionaram empregos, diretos e indiretos, para a população local, fazendo, assim, com que mais pessoas passassem a trabalhar e a ter renda por causa do turismo. Além disso, outros benefícios econômicos, como a dinamização do comércio local, e aumento de poder de compra dos residentes são observados, como percebido pelo entrevistado a seguir:

\footnotetext{
"Trouxe o benefício bastante que as pessoas a maioria assim uma quantidade foram empregada, então, no que empregam mais gente entendeu? Então melhora pra [sic] o comércio porque as pessoas já têm mais dinheiro, já tem uma estabilidade, no final do mês vou receber então eu vou comprar, então melhorou por conta disso, que beneficou a população nessa questão" (E1).
} 
Assim, as pessoas dos povoados da Rota Ecológica passam a não depender mais de uma única fonte de renda; agora vários membros da família trabalham com o turismo direta ou indiretamente e colaboram com a renda da família, fazendo com que as atividades econômicas tradicionais trabalhem concomitante com as complementares, e, em alguns casos, o trabalho com o turismo é a principal fonte de renda de algumas famílias.

Outro aspecto mencionado foi que pescadores locais passaram a fornecer pescados rotineiramente às pousadas, e alguns outros adaptaram suas jangadas para fazer passeios às piscinas naturais, também gerando alternativas de renda para os autóctones. Pedreiros, eletricistas e demais trabalhadores da construção civil também passaram a trabalhar neste setor na construção de empreendimentos ligados ao turismo.

Por outro lado, o custo de vida de lugares que se tornam turísticos em geral fica mais caro, e a população percebe o impacto no aumento do preço de seus produtos básicos e alguns serviços. Todos estes fatores foram relatados pelos entrevistados neste estudo e foi verificado que os impactos quanto aos aspectos econômicos são pontos centrais das opiniões sobre o turismo na Rota Ecológica, conforme explicado pelo entrevistado abaixo:

\begin{abstract}
"Aí mudou o custo de vida, aumentou realmente. É como se fosse o camarão, camarão que é uma comida típica da região, a agulhinha, hoje porque, porque as pousadas compram camarão, o polvo por exemplo, quem queria polvo? O polvo era sete reais, oito reais o quilo, hoje é trinta reais, por quê? Porque a pousada não deixa ninguém passar na porta com um polvo, "epa [sic], traga pra cá que eu quero", é cardápio do hotel. Então isso reajustou também, aumentou o custo de vida" (E2).
\end{abstract}

Já em relação aos aspectos sociais, foi verificado que o posicionamento de alguns entrevistados indica a existência de uma visão crítica e mais politizada em relação às mudanças dos lugares da Rota Ecológica por causa do turismo das pousadas. Tal fato talvez esteja acontecendo neste trecho do litoral pela presença de instituições como o ICMBIO que organiza reuniões e consultas públicas sobre a situação local, e pela ação de outras organizações que vem atuando localmente, buscando fomentar a participação da população, tentando ajustar os seus interesses com os interesses da iniciativa privada local.

Pela atividade turística ainda acontecer nesses lugares em pequena escala, e pela relação mais próxima existente entre os pousadeiros e as comunidades - se comparado com o turismo de massa, mais impessoal -, o que permite aos residentes saber quem são as pessoas que estão por trás da oferta turística, os moradores dessa região parecem mais aptos a entender as mudanças que estão em curso no lugar, pois os pequenos povoados são parte central dos atrativos turísticos locais. Além disso, a chegada do turismo também dinamizou o comércio local e contribuiu para a abertura de novas lojas que atendem tanto à população local quanto aos turistas, sem precisar 
fazer maiores deslocamentos para comprar alguns tipos de produtos em outros lugares. Após a chegada das pousadas, na percepção dos entrevistados também houve melhoria em estradas, fornecimento de energia, e na telefonia móvel, ainda que seja insuficiente, especialmente nos povoados de Passo de Camaragibe, como Barra de Camaragibe e Marceneiro.

Por outro lado, já existe na região uma discussão sobre o embate entre comunidade local e pousadeiros em torno do acesso a determinados trechos de praia onde se localizam algumas pousadas como exemplificado na fala do morador de São Miguel dos Milagres:

\begin{abstract}
"Então o pessoal chega de fora, loteia e tal, faz loteamento, mas deixe os espaço [sic] que você já encontrou entendeu? Que é o do acesso das pessoas que foi nascido, que foi criado, foi convivido ali, mas eles tiram" [...] (E1).
\end{abstract}

Apesar das críticas dos problemas de relacionamento que surgiram entre pousadeiros e residentes, alguns entrevistados, principalmente dos povoados do município de São Miguel dos Milagres, observam como positivo a presença das pousadas no seu lugar, mas, reivindicando sempre uma boa convivência e diálogo entre as pousadas e a comunidade.

As principais observações negativas verbalizadas pelos entrevistados foram: 1) As tentativas de impedimento de acesso a alguns trechos de praia, principalmente em lugares onde os pescadores frequentam e deixam seus equipamentos de trabalho; 2) inibição dos moradores em frequentar determinados trechos da orla dos seus povoados; 3 ) relativa perda de poder perante a iniciativa privada; 4) pouco envolvimento das pousadas em projetos sociais direcionados a população local - os que existem eles percebem como insuficientes; 5) ocupação de terrenos mais distantes da orla por alguns moradores, pois a frente de praia está valorizada pelo turismo, não só das pousadas, mas também por parte de segundas residências, e, por último, 6) o aumento de preços de alguns produtos básicos, de pescados e serviços, como o transporte no lugar por taxistas. A percepção, e menção, a respeito desses problemas de alguma forma parece indicar que os entrevistados guardam certa reserva sobre o que o turismo está fazendo com o lugar deles.

Ao se analisar as críticas que são muito difundidas, a respeito dos impactos negativos que o turismo normalmente causa nos lugares nos quais ele se implanta, a variedade de benefícios percebidos pelos entrevistados residentes da Rota Ecológica, claramente influenciaram uma visão amplamente positiva sobre o desenvolvimento turístico nos lugares onde moram. De um modo geral, os entrevistados não comunicaram uma visão de que o turismo das pousadas tivesse se apropriado do lugar deles, apesar das críticas pontuais que foram feitas. De certa maneira, já era de se esperar que fosse assim, considerando-se que a oferta turística dessas pousadas está associada a uma orientação alternativa do desenvolvimento turístico. A situação provavelmente seria bem diferente se a área da Rota Ecológica 
tivesse sido inserida primeiramente através do modelo de turismo de massa, incluindo resorts.

Constatou-se com este estudo que após a implantação das pousadas da Rota Ecológica, as comunidades locais têm presenciado transformações econômicas, sociais, culturais e ambientais. De locais pacatos e normalmente habitados apenas por nativos, passaram a ser destinos turísticos de padrão internacional, de conforto e luxo, atraindo pessoas cujo comportamento no lugar contrasta diretamente com as rotinas diárias do cotidiano dos autóctones, o que confere novas características aos lugares visitados, com implicações para a forma como os nativos usam e percebem o seu próprio lugar.

\section{Considerações finais}

Apesar do olhar local dos entrevistados em relação às pousadas da Rota Ecológica e a turistificação desencadeada por elas ser essencialmente positiva, foi percebido que na prática é a iniciativa privada que detém o poder de decisão sobre o que vem sendo feito nestes lugares em relação à atividade turística. Foram estas pousadas que trouxeram o boom turístico para a região e são elas também que têm provocado alguns problemas na visão da população local. No estudo foi verificado que as falas dos entrevistados frequentemente sugerem que a comunidade receptora demonstra alguns incômodos provocados pelas pousadas aos residentes desses lugares. Porém, foi observado que as reclamações são pontuais e que pelo envolvimento e engajamento da população local com o turismo, através de organizações da comunidade civil e das ONG, os problemas vêm sendo contornados.

Essa é uma situação muito diferente do que ocorre em lugares onde há o predomínio de uma orientação de turismo voltado a formas massivas, nos quais a participação e envolvimento popular não são favorecidos, o que termina por gerar mais rapidamente antagonismo entre os residentes e a atividade turística.

O estudo identificou, por outro lado, que a comunidade local absorveu bem a ideia do seu lugar como lugar turístico e, com base nessa percepção, vem oferecendo serviços para a atividade turística, o que contribui para uma melhor condição de vida local. São restaurantes simples, pequenas pousadas e estabelecimentos comerciais que direta ou indiretamente oferecem serviços demandados pelo turismo, dinamizando a economia destes pequenos povoados litorâneos.

Claramente associado a essa tendência de desenvolvimento turístico recente em praticamente todo o mundo, o tipo de oferta turística e experiência proporcionadas aos visitantes pelas pousadas da Rota Ecológica, tem gerado uma percepção que até certo ponto se diferencia do turismo de massa. A diferença principal parece estar no maior envolvimento da população da Rota Ecológica com o turismo, gerando assim uma aproximação entre a iniciativa comercial e as comunidades. 
Constatou-se, assim, que a Rota Ecológica está mais alinhada a uma orientação alternativa de turismo do que a uma orientação massiva. Essa característica parece ser o fator principal que tem contribuído para que os entrevistados da comunidade local tenham desenvolvido um olhar local predominantemente favorável à presença das pousadas da Rota Ecológica e ao tipo de turismo trazido por elas, apesar das críticas feitas.

\section{Referências}

ARAUJO, L.M.; MOURA, F.B.P. A expansão do turismo na zona costeira nordestina: crescimento econômico, degradação ambiental e erosão cultural. In: CORIOLANO, L.N.M.T.; VASCONCELOS, F.P. (Orgs.). O turismo e a relação sociedade-natureza: realidades, conflitos e resistências. 1. ed. Fortaleza: EdUECE, 2007, p. 94-114.

ARCHER, B.; COOPER, C. Os impactos positivos e negativos do turismo. In: THEOBALD, William F. Turismo global. São Paulo: Senac, 1998.

BAKER, M.J.; SAREN, M. Marketing theory: a student text. London: Sage, 2010.

BANCO DO NORDESTE DO BRASIL. Pólo Costa dos Corais. Disponível em: $<$ http://www.bnb.gov.br/content/aplicacao/prodetur/polos/gerados/prodetur polos alagoas.asp > Acesso em: 10 out 2011.

BANCO DO NORDESTE DO BRASIL. Regulamento operacional do Prodetur/NE II. Disponível em: $<$ http://www.bnb.gov.br/content/aplicacao/PRODETUR/Downloads/_docs/ rop 1 parte geral.pdf> Acesso em: 10 out 2011.

BANCO DO NORDESTE DO BRASIL. Regulamento operacional do Prodetur/NE II.. Disponível em: $<$ http://www.bnb.gov.br/content/aplicacao/PRODETUR/Downloads/_docs/ rop 1 parte geral.pdf> acesso em 10/10/2011.

BARRETTO, M. Manual de iniciação ao estudo do turismo. Campinas: Papirus, 1995 (Coleção Turismo).

BIHU, W.; MIN, Z.; XIAOLI, P. Research on residents' perceptions on tourism impacts and attitudes: a case study of Pingyao Ancient City. Conference of the International Forum on Urbanism. "6th Conference of the International Forum on Urbanism (IFoU): TOURBANISM, Barcelona, 25-27 gener" Barcelona: IFoU, 2012, p.1-10.

BOYER, M. História do turismo de massa. Trad: Viviane Ribeiro. Bauru: EDUSC, 2003.

BRANDÃO, P.R.B. Territórios do turismo, territórios de todos?: Um estudo comparado sobre urbanização e formação de territórios em balneários turísticos do Nordeste do Brasil. 2013.Tese (Doutorado) - UFPE, Recife. Disponível em: $<$ https://www.ufpe.br/posgeografia/images/tese\%20ppgeo\%20ufpe\%20paulo\%20 r\%20b\%20brando\%202013.pdf>. Acesso em: 20 jun. 2014.

BRASIL, Ministério do Turismo. Turismo sustentável e alívio da pobreza no Brasil: reflexões e perspectivas. Brasília: Ministério do Turismo, 2005. Disponível em:< http://livros01.livrosgratis.com.br/tu000017.pdf>. Acesso em: 01 mai. 2013. 
CAMÊLO, A.R.S. Gestão institucional do turismo no polo costa dos corais nos municípios de Passo de Camaragibe, São Miguel dos Milagres e Porto de Pedras - Alagoas. Originalmente apresentada como monografia ao curso de Geografia, Universidade Federal de Alagoas, Maceió: AL, 2013.

CARVALHO, R.K.A. Pousadas de charme como uma alternativa para o turismo sustentável em São Miguel dos Milagres - AL. Maceió, AL, 2014. 63 f.: Monografia (Bacharelado em Geografia) - Universidade Federal de Alagoas, Instituto de Geografia, Desenvolvimento e Meio Ambiente, Maceió, AL, 2014.

CONWAY, D.; TIMMS, B.F. Slow Tourism at the Caribbean's Geographical Margins. Tourism Geographies: An International Journal of Tourism Space, Place and Environment, 14:3, p. 396-418, 2012.

COOPER, C.; HALL, C.M.; TRIGO, L.G.G. Turismo contemporâneo. Rio de Janeiro: Elsevier, 2011.

CORDEIRO, I.; BENTO, E.; BRITTO, C. Turismo e desenvolvimento sustentável: considerações sobre o modelo de resorts no litoral nordeste do Brasil. Caderno Virtual de Turismo. Rio de Janeiro, v. 11, n. 3, p.355-369, dez. 2011.

CORIOLANO, L.N.M.T.; et. al. Arranjos Produtivos Locais do Turismo Comunitário: atores e cenários em mudança. Fortaleza: EdUECE, 2009.

COSTA, C. An Emerging Tourism Planning Paradigm? A Comparative analysis between town and tourism planning, International Journal of Tourism Research, vol.3, n. 6, pp. 425- 441, 2001.

CRUZ, R.C. Introdução à Geografia do Turismo. 2ed. São Paulo: Roca, 2003.

CRUZ, R.C. Planejamento Governamental do Turismo: convergências e contradições na produção do espaço. In: LEMOS, A.I.G.; ARROYO, M.; SILVEIRA, M.L. América Latina: cidade, campo e turismo. 1ㄹ ed. Buenos Aires: Consejo Latinoamericano de Ciências Sociales (CLACSO); São Paulo: Universidade de São Paulo, 2006.

DOXEY, G.V. A causation theory of visitor-resident irritants, methodology and research inferences. The impact of tourism. Sixth Annual Conference Proceedings of the travel research association. San Diego, CA, 1975.

DUDA, J.I.M. Polos de turismo em regiões subdesenvolvidas: estudo de caso do polo Costa dos Corais, Alagoas. Dissertação (Mestrado) Maceió, AL: UFAL, 2013.

ESTADO DE ALAGOAS. Lei № 7.231, de 7 de janeiro de 2011. Disponível em: $<$ http://www.gabinetecivil.al.gov.br/legislacao/leis/leis-ordinarias/2011/lei-

ordinaria-7.231>. Acesso em 03 jul. 2012.

EVANS, A. Sustainable and Alternative Tourism. In: ROBINSON, P.; HEITMANN, S.; DIEKE, P.U.C. (Orgs.). Research themes for tourism. UK: MPG Books Group, 2011, p 69-86.

EWALD, A.P. Fenomenologia e Existencialismo: articulando nexos, costurando sentidos, Estudos e Pesquisas em Psicologia, vol. 8, n. 2, pp. 149-165, 2008. Disponível em: < http://www.revispsi.uerj.br/v8n2/artigos/html/v8n2a02.html>. Acesso em: 15 ago 2016. 
FRAGA, F.F. A Expansão do Turismo em São Miguel dos Milagres - AL: contribuições e obstáculos ao desenvolvimento local. Dissertação (Mestrado) João Pessoa, PB: UFPB, 2013.

GIDDENS, A. As consequências da modernidade. Tradução: Raul Fiker. São Paulo: editora UNESP, 1991.

HARVEY, D. Condição pós-moderna: uma pesquisa sobre as origens da mudança cultural. Trad: Adail Ubirajara sobral e Maria Stela Gonçalves. 23. ed. São Paulo: Edições Loyola, 2012.

HEITMANN, S.; POVEY, G.; ROBINSON, P. Slow food, Slow cities and Slow Tourism. In: DIEKE, P.U.C.; HEITMANN, S.; ROBINSON, P. (Org.). Research themes for tourism. UK: MPG Books Group, 2011, p 114-127.

KNAFOU, R. Turismo e território: Por uma abordagem científica do turismo. In: RODRIGUES, A.B.(Org.). Turismo e geografia: Reflexões teóricas e enfoques regionais. São Paulo: Hucitec, 1996, p. 62-74.

KRIPPENDORF, J. Sociologia do turismo: para uma nova compreensão do lazer e das viagens. Tradução: Contexto traduções. 3ª ed. São Paulo: Aleph, 2009.

LYON, D. Pós-modernidade. 2. ed. 1a ed: 1998. Trad: Euclides Calloni. São Paulo: Paulus, 2005.

MARSON, D. From Mass Tourism to Niche Tourism. In: ROBINSON, P.; HEITMANN, S.; DIEKE, P.U.C. (Orgs.). Research themes for tourism. UK: MPG Books Group, 2011, p 1-15.

MASTER-ECOPOLIS. Um território desejável: compromisso integrado para a Costa dos Corais. Alagoas: 2010.

MENDONÇA, M.L.M. Turismo sustentável: classes sociais e subjetividade. In: MONTORO, T.S. (Org.). Cultura do turismo: desafios e práticas socioambientais. Brasília: Thesaurus, 2003.

MERLAU-PONTY, M. Fenomenologia da percepção. Tradução de Carlos Alberto Ribeiro de Moura. $2^{2}$ ed. São Paulo: Editora Martins Fontes, 1999.

NICOLETTI, L. Turismo e desenvolvimento local sustentável. In: MONTORO, T.S. (Org.). Cultura do turismo: desafios e práticas socioambientais. Brasília: Thesaurus, 2003.

OLIVEIRA, E.S. Impactos socioambientais e econômicos do turismo e suas repercussões no desenvolvimento local: o caso de Itacaré -Bahia. Dissertação (Mestrado) Ilhéus, BA: UESC, 2008.

ORGANIZAÇÃO MUNDIAL DO TURISMO (OMT). Barómetro OMT del turismo mundial. Vol. 4, 2006. Disponível em: < http://www.worldtourism.org/facts/wtb.html>. Acesso em: 01 mai. 2013.

PANOSSO NETTO, A. O que é turismo. São Paulo: Brasiliense, 2010.

RAMOS, S. Turismo e desenvolvimento local: uma "viagem de inclusão?". In: RAMOS; S.P.; CERDAN; L.M. i. Turismo, políticas e desenvolvimento humano. Porto Alegre: Asterisco, 2010.

RODRIGUES, A.B. Turismo e Espaço: rumo a um conhecimento transdisciplinar. 2ª ed. São Paulo: Hucitec, 1999. 
RODRIGUES, A.B. Turismo e territorialidades plurais - lógicas excludentes ou solidariedade organizacional. In: LEMOS, A.I. et al. América Latina: cidade, campo y turismo. San Pablo: Clacso, 2006.

ROTEIROS DE CHARME. Associação de Hotéis Roteiros de Charme. Em: $<$ http://www.roteirosdecharme.com.br/hoteis.php >. Acesso em 14 de setembro de 2012.

SILVA, G.D. Memórias de São Miguel dos Milagres. Sem editora: São Miguel dos Milagres, 2012.

URRY, J. O olhar do turista - lazer e viagens nas sociedades contemporâneas. Trad: Carlos Eugenio Marcondes de Moura.2a. ed. São Paulo: SESC/Studio Nobel, 1996.

VASCONCELOS, D.A.L. Sol, Praia e a "Destinação" da Cidade: Compreendendo a Turistificação de Maceió-Alagoas-Brasil. 2017. Tese (Doutorado) - UFAL, Maceió.

XAVIER, H. A percepção geográfica do turismo. São Paulo: Aleph, 2007.

ZAOUOAL, H. Do turismo de massa ao turismo situado: quais as transições?

Caderno Virtual de Turismo, Rio de Janeiro, Vol.8, n.2: 1-14, 2008.

\section{Notas:}

${ }^{1}$ Compradores dos serviços turísticos oferecidos pelo Mercado e agente receptor do processo.

${ }^{2}$ Empresas fornecedoras dos serviços turísticos ofertados aos turistas e agente provedor do processo.

${ }^{3}$ Agentes do poder público ou da iniciativa privada contratados pelo agente de Mercado.

OBS: Produziu-se este artigo com base em uma Dissertação do Programa de Pós Graduação em Arquitetura e Urbanismo da Universidade Federal de Alagoas.

Ana Rísia Soares Camêlo: Universidade Federal de Alagoas, Maceió, AL, Brasil.

E-mail: anarisia@hotmail.com

Link para o currículo Lattes: http://lattes.cnpq.br/3419675609798570

Lindemberg Medeiros de Araujo: Universidade Federal de Alagoas, Maceió, AL, Brasil.

E-mail: Imdeirosbr@gmail.com

Link para o currículo Lattes: http://lattes.cnpq.br/1427075376799452

Data de submissão: 30 de agosto de 2016

Data de recebimento de correções: 17 de janeiro de 2018

Data do aceite: 17 de janeiro de 2018

Avaliado anonimamente 